\title{
An Unusual Case of Hypercalcaemia
}

\section{Dr. G. Pink (CT2 ${ }^{1}$ ); Mr. R. Athavale (Consultant Gynaecology Oncology²); Dr. S. Sah (Consultant Histopathologist ${ }^{2}$ ); Dr. R. Mahto (Consultant Endocrinologist ${ }^{1}$ )}

${ }^{1}$ Warwick Hospital, South Warwickshire Foundation Trust; ${ }^{2}$ University Hospital Coventry and Warwickshire NHS Trust

\section{Case Presentation:}

A 19 year old female presented to A\&E with a three week history of nausea, vomiting and constipation. She was noted to have high serum calcium of $4.1 \mathrm{mmol} / \mathrm{L}$. There was no family history of note and prior to this illness she had been fit and well with no regular medications. Initial examination revealed a suprapubic mass thought to be a distended bladder.
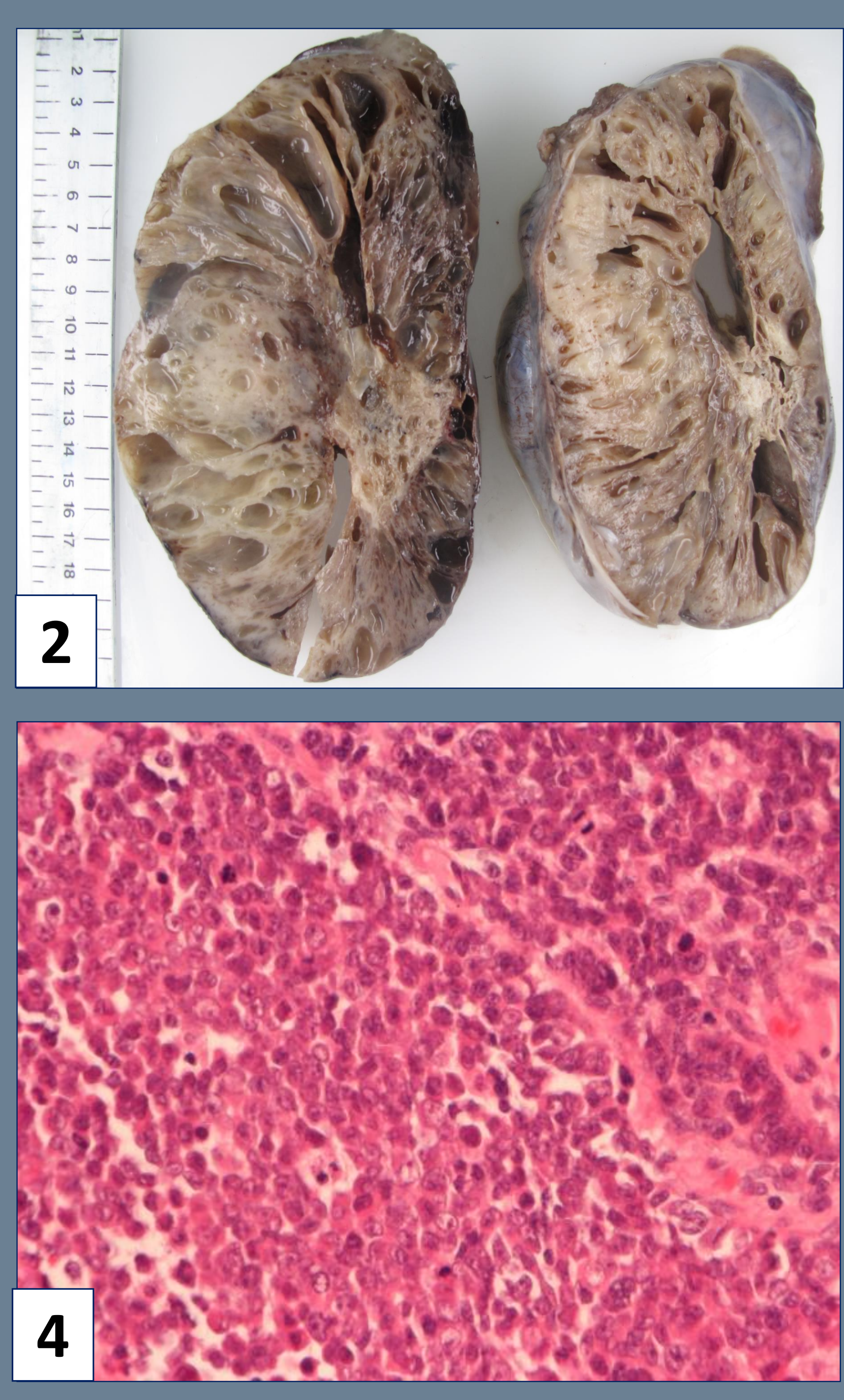

Figure 2: Cut surface of left ovarian tumour showing solid and cystic components with microcysts and macrocysts. Figure 3: Low power view showing tumour with diffuse sheeted growth pattern and many follicle-like structures containing eosinophilic fluid. Figure 4: High power view showing tumour cells with hyperchromatic nuclei, scant cytoplasm and frequent atypical mitosis figures. Figure 5: Tumour showing diffuse nuclear immunoreactivity with WT1

\section{Investigations:}

Initial investigations revealed a suppressed PTH of $<0.6 \mathrm{pmol} / \mathrm{L}$. U\&E, vitamin $\mathrm{D}, \mathrm{TSH}$, serum ACE and cortisol were within normal range. An USS and CT scan of the abdomen \& pelvis revealed a $17 \mathrm{~cm}$ left ovarian mass. Her CA125 was markedly raised at 320 $\mathrm{ku} / \mathrm{L}$.

Shown in figure 1 is a slice of the CT scan showing the pelvic mass at presentation, the macroscopic appearance of her left ovary from initial resection is shown in figure 2 and the histological appearance of the tumour shown in figure 3,4 \& 5 .

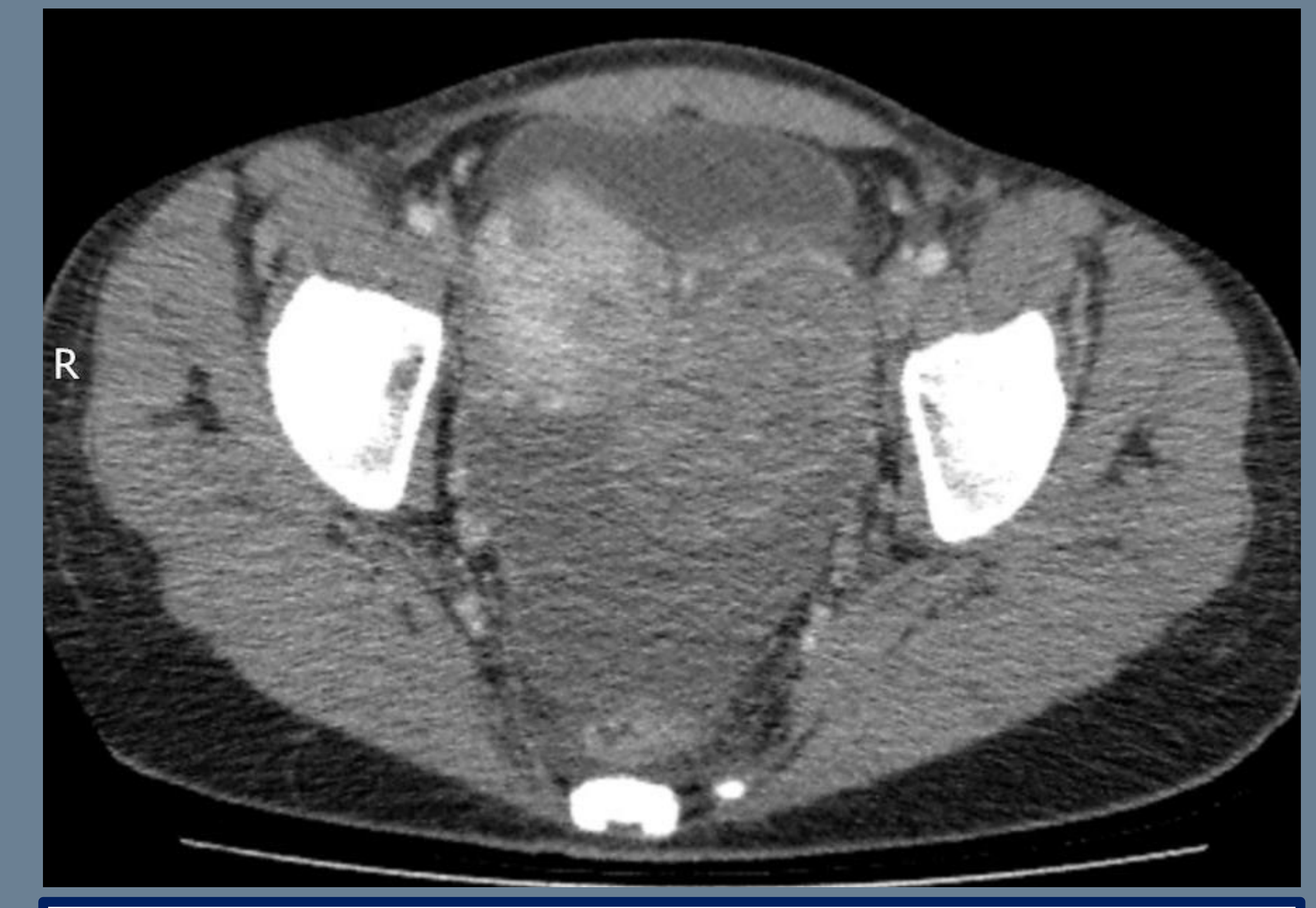

Figure 1: CT abdomen \& pelvis image showing pelvic mass

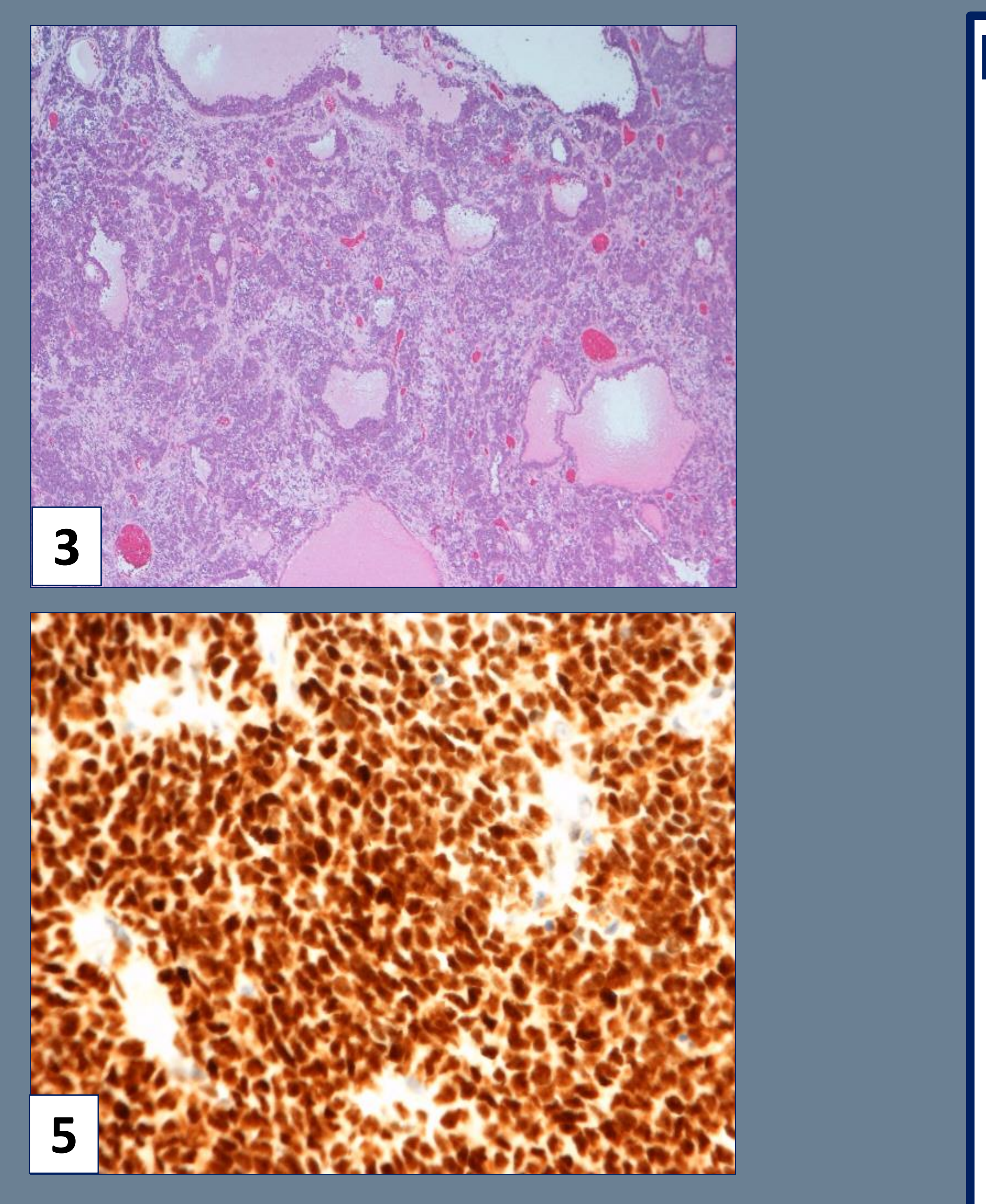

Diagnosis and Treatment:

Hydration and pamidronate infusion brought her serum calcium down to $2.53 \mathrm{mmol} / \mathrm{L}$. She was transferred to the care of the gynaecology team and her case was discussed in the

MDT. She underwent a laparotomy and left salphingooopherectomy. A left $20 \mathrm{~cm}$ ovarian mass was excised along

with all macroscopic evidence of the tumour. Histology confirmed an ovarian small cell carcinoma of hypercalcaemic type (OSCCHT), FIGO stage Ilb. Later PET scanning revealed scattered metabolically active peritoneal nodules and the stage was updated to 3b-4. Genetics confirmed a SMARCA4 gene inactivating mutation.

Our patient was managed by the Teenage Cancer Trust in light of her age and referred for palliative combination chemotherapy. A follow up PET scan following 4 cycles of chemotherapy showed marked reduction in the size of metabolically active pelvic soft tissue masses, peritoneal nodules and lymph nodes.

Diagnosis carries a poor prognosis $(6.5 \%$ survival in stage $2-4$ disease [1]); there have been scattered case reports describing cure following surgical resection with aggressive multi-agent chemotherapy $[2,3]$.

\section{Hypercalcaemia and Gynaecological Malignancies: \\ Hypercalcaemia is an uncommon occurrence in gynaecological malignancies, occurring in only $5 \%$ of ovarian cancers [4]. It is more common within the rarer ovarian cancer subtypes and indeed present in $66 \%$ of OSCCHT cases; mediated by parathyroid hormone related peptide [5].}

This rare and aggressive tumour type affects young females and in half of cases has extra-ovarian spread at diagnosis [1]. OSCCHT shows a peak of cases in the third decade of life, with a median age of diagnosis of 24 years [6]. The commonest presenting complaints are of abdominal pain, weight loss and abdominal swelling [5].

First described in 1982, OSCCHT has until recently has evaded cytogenetic or molecular classification. In cases of OSCCHT a familial tendency for cases has long been recognised, with 1 in 2 women also having a first degree relative with cancer [5]. In 2014 the pathology 'enigma' was decoded after deletion mutations in the chromatin-remodelling gene SMARCA4 (encoding BRG1) were identified. This catalytic subunit is present in all eukaryotes and associated with the SWI/SNF complex that remodels chromatin, in order to regulate gene expression

[7]. Germline and somatic mutations of this gene have been shown in further studies following its discovery [8,9]. This gene has been linked to various other human cancer types (including breast, prostate, lung, pancreas and colon) and is mutated in most rhabdoid tumours [10].

\section{References:}

[1] Young RH, Oliva E, Scully RE. Small cell carcinoma of the ovary, hypercalcemic type: a clinicopathological analysis of 150 cases. The American journal of surgical pathology. 1994 Nov 1;18(11).

[2] Pressey JG, Kelly DR, Hawthorne HT Successful treatment of preadolescents with small cell carcinoma of the ovary hypercalcemic type. Journal of pediatric hematology/oncology. 2013 Oct 1;35(7).

[3] Christin A, Lhomme C, Valteau-Couanet D, Dubrel M, Hartmann O. Successful treatment for advanced small cell carcinoma of the ovary. Pediatric blood \& cancer. 2008 Jun 1;50(6).

[4] Piura B. Hypercalcemia in malignancies of the female genital tract. Harefuah. 2008 Mar; $147(3)$

[5] Distelmaier F. et al. Ovarian small cell carcinoma of the hypercalcemic type in children and adolescents. Cancer. 2006 Nov 1;107(9).

[6] Longy M, Toulouse C, Mage P, Chauvergne J, Trojani M. Familial cluster of ovarian small cell carcinoma: a new mendelian entity?. Journal of medical genetics. 1996 Apr 1;33(4).

[7] Foulkes WD, Clarke BA, Hasselblatt M, Majewski J, Albrecht S, McCluggage WG. No small surprise-small cell carcinoma of the ovary, hypercalcaemic type, is a malignant rhabdoid tumour. The Journal of pathology. 2014 Jul 1;233(3).

[8] Jelinic P. et al. Recurrent SMARCA4 mutations in small cell carcinoma of the ovary. Nature genetics. 2014 May 1;46(5).

[9] Ramos P. et al. Small cell carcinoma of the ovary, hypercalcemic type, displays frequent inactivating germline and somatic mutations in SMARCA4. Nature genetics. 2014 May 1;46(5).

[10] Medina PP, Sanchez-Cespedes M. Involvement of the chromatin-remodeling factor BRG1/SMARCA4 in human cancer. Epigenetics. 2008 Mar 24;3(2) 